\title{
Power Quality Analysis at Pumping Stations Network In Egypt
}

\author{
Prof. Radwan H. Abdel-Hamid, \\ Faculty of Engineering, \\ Helwan University.
}

\author{
Prof. Sobhi M. Ahmed Farrag \\ Faculty of Engineering, Monofia, \\ University.
}

\author{
Prof. Mohamed A. Helal, \\ Mechanical and Elect. Research Ins. \\ National Water Research Center \\ Ashraf M. Elsotohy, \\ B.Sc, research Assistant, \\ Mechanical and Elect. Research Ins.
}

\begin{abstract}
This paper aims mainly to implement the power quality issues and impact on the pumping stations networks supervised by the ministry of Water Recourses and Irrigation in Egypt. The paper outlines the strategy of monitoring the power system disturbances at these stations with special emphasis on those disturbances influencing the performance of the pumping units. Because the pump stations network is large (more than 1500 pump stations) with different hydraulic load nature, this paper adopted a pilot project to conceive the power quality study. Two large pump stations are selected for this study at two different locations. The rating of the pumping units ranges between $475 \mathrm{~kW}$ and I MW for each unit at an operating voltage ranges between $6.6 \mathrm{kV}$ and $11 \mathrm{kV}$. A special diagnosis system is described and installed at the selected pilotipump stations for long periods to cover the seasonable load system at these stations. Based on that system a comprehensive data of unpredictable disturbances are recorded, examined and analyzed to clarify the power quality picture at the selected stations. This study also includes the lack of industry standards and performance behavior of the drive motors at the pumping station network. Problems conducted for investigation included all type of voltage disturbances such as voltage surges and impulses, voltage sags, harmonic invasion, flickering, and P.F quality. It is hoped that this study will be of special benefits to the Ministry and other private sectors growing now in the field of cultivated lands.
\end{abstract}

Manuscript received from Eng. Ashraf $M$. Elsotohy

Accepted on : 20/1/2001

Engineering Research Journal Vol 24,No 2, 2001 Minufiya University, Faculty Of Engineering , Shebien El-Kom, Egypt, ISSN 1110-1180 


\section{Introduction}

There are about 1500 pumping stations in Egypt widely spread over the country to cover the national requirements of irrigation and drainage [1]. The network includes modern and traditional pumping units since late 40 's at a variety of nameplate data.

The pumping stations are either powered by low voltage $(380 \mathrm{~V})$ or medium voltage supply ranging between $(3.3$ up to $11 \mathrm{kV})$. The rating of individual units varies between $16 \mathrm{~kW}$ and $2 \mathrm{MW}$. The network suffers poor supply quality mainly due to sharing the supply with other distribution systems in the neighborhood. In addition maintenance and operation problems may lead to system faults and hence interruption of the power supply. It is evident that the most important problems worth studying are:

i) Voltage surges and impulses: They are characterized by relatively high frequency voltage excursions of short duration, usually less than one-half cycle $(10 \mathrm{~ms})$. If the impulse is of a significant magnitude and duration, it can cause malfunction to control elements and damage the insulation of the drive motors and other equipment.

ii) Waveshape faults: Wave-shape faults are longer in duration than impulses. They are often sub-cycle distortion of the ac sinusoid. This type of disturbance can last for a fraction of the single cycle period or they can continue for hundreds of milliseconds, hours, or even days.

iii) Voltage surges and sags: Surges are that rms. voltage levels which goes above $+5 \%$, while sags are those voltage levels which go below $-10 \%$. The duration is generally from few a few cycles to a few seconds.

iv) Harmonic invasion: Harmonic components in driving machines have special symptoms problems including overheating of motors and transformers, false circuit breaker trips, fuse blowing, unexplained behavior of relays. Since utility systems are designed to minimize phase imbalance and harmonic distortion, the problems of harmonic distortion is more likely raised by the consumers and/or vicinity loads rather than the power source.

v) Flickering: IEC 1000-3-3 defines flicker as the noticeable variation in intensity of a light source. On the utility distribution system, flicker occurs in response to variations in distribution voltage amplitude, hence the common designation (voltage flicker). Voltage flicker is defined as a percentage of the rms. Fundamental voltage amplitude. The threshold of perception varies greatly with the frequency of the flicker. Psychological studies show flicker to be most noticeable in the range of six to eight Hertz.

These factors are decisive for the operation of the a.c machine driving the pumping units at these stations. The power factor is also an important factor in the power quality measures. The pumping stations show a margin of P.F variation between 0.75 to 0.85 lagging depending on the scale of rating and the speed of the driving motors. In terms of money, the Ministry of Water Resources and irrigation has to pay annually perhaps millions of extra L.E to cover the bad quality of the supply and the electricity bill including the penalties 
imposed by electricity authority for running the pumping stations at a power factor less than the prescribed values. For these reasons, this research work is addressed towards the following important objectives:

1) Scanning and exploring the exiting pumping stations in order to select some preliminary stations to launch this research.

2) Setting up an integrated system for reliable on line monitoring and measurements including:

a) System disturbances of sags, surges, impulses, and flickering.

b) Pattern of electrical energy consumption (balanced, unbalanced).

c) Harmonics invasion on the power supplies.

d) Power factor records.

3) Analyze and evaluate the system and propose the necessary recommendations for power quality and power factor improvement. The following pumping stations were selected:

a) Abu - Almonagga station (1): 5 whits, each has $476 \mathrm{~kW}, 6 \mathrm{kV}, 55 \mathrm{~A}, 1450$ r.p.m, $P . F=0.87$, vertical pump installation, $8.5 \mathrm{~m}^{3} / \mathrm{sec}, H=2.5 \mathrm{~m}$.

b) Salhia station (2): 6 units, each has: $1 M W, 11 k V, 63 A, 987$ r.p.m, P.F=0.87, vertical pump installation, $1.5 \mathrm{~m}^{3} / \mathrm{sec}, H=50 \mathrm{~m}$.

The reasons for selecting these stations are to cover different types of pumping, different load nature, and different levels of operating voltage including $(6 \mathrm{kV}$ up to $11 \mathrm{kV}$ ) supply systems.

\section{Load Nature}

The load characteristics of pumping units are sophisticated depending on the type of pump, speed, the total operation head $H$, and the power flow $Q$ [2]. Since the driving machines are 3-phase induction motors, the speed of the pump is almost constant and the performance of the pump should approximately follow the pattern characteristics of fans. The actual performance, however, is not easily predictable unless field measurements are obtained. The nature of pumping loads may be classified to the following dominant applications:

a) Irrigation Pumping Station

b) Drainage Pumping Stations:

\section{3-Power Quality Identification}

For many years the equation defining power quality was very simple:

\section{Power Quality $\cong$ Reliability}

This definition is no longer reliable and the proper categories of power quality variation should be set up as the first step to understand the problem of power quality. The power quality variations fall into two basic categories [3-11]: 


\section{i- Disturbances:}

This is measured by triggering on an abnormality in the voltage or the current. Transient voltages may be detected when the peak magnitude exceeds a specified threshold. RMS voltage variations (e.g. sags or interruptions) may be detected when the RMS variation exceeds a specified level.

\section{ii- Steady State Variations :}

These include normal RMS voltage variations and harmonic distortion. These variations must be measured by sampling the voltage and/or current over time. The information is best presented as a trend of the quantity (e.g. voltage distortion) over time and then analyzed using statistical methods (e.g. average distortion level $95 \%$ probability of not being exceeded, etc.).

\section{4- Influence of Power Quality on Pumping Stations}

It has been confirmed by NEMA [12], that a.c drive machines are typically designed to perform well over the continuous range of operation with minimum voltage and frequency variation. Outside the predetermined range, the drive motor of the pumping unit or any other typical load at the station may not be able to keep the speed or other critical parameters necessary to the process. Switchgear attached to the drive machines may also drop out because of voltage variation causing the system sometimes to shut down. The following disturbances are usually expected at the water pumping stations:
i) Voltage imbalance
ii) Frequency variation
iii) Harmonics
iv) Wave-shape faults
v) Voltage surges and sags
vi) Power factor problent

\section{5- Diagnosis System}

To get the best diagnosis records profile for system disturbances, an integrated power line monitor [13] has been launched at the selected sites of the pilot project. Figure (1) depicts the single line diagram of the diagnosis system presented in this paper. It is seen from the figure that the monitoring system consists of a data base engine (monitor instrument) housed in a rugged weatherproof enclosure with a storing capacity of 4 Mbytes of internal RAM and 120 Mbytes built in hard disk drive. The monitor has 10 monitoring channels; ( 5 voltage) and ( 5 current) for simultaneous voltage and current records. The data are collected using cable pallet including 5 voltage transducers and 5 clamp-on current transducers with safety connectors. The collected data can be downloaded from the monitor to the Personal Computer (PC) through the standard series RS-232 interface and special Microsoft Windows-based Reliable Power Meter (RPM) software. The system is easily adapted to store and analyze data collected over short or long term monitoring without running out of recording media or memory buffers. Resolutions of typical monitoring periods are setup as 
- I Hour has a resolution of 1 sec sampling data rate.

- 12 Hour has a resolution of 15-sec sampling data rate.

- I month has a resolution of 15 min sampling data rate.

- I year has a resolution of 4 hoirs sampling data rate.

The system provides full information for the captured power disturbances including:

- High impulses

- Wave shapes fault

- Voltage sags, swells (high voltage variation)

- Harmonics

All these information are recorded in a standard tolerance events (envelope) curve to determine whether the disturbances are within the standard predetermined values or not.

In addition, information regarding the power flow parameters such as

- Voltage and Currents.

- $k W, k V A, k v a r s$,

- $P F$, and THD (total harmonic distortion)

can be obtained. These information will be of great help to determine what the problems at the pumping station are, where and why they occur, what action should be taken to solve these problems.

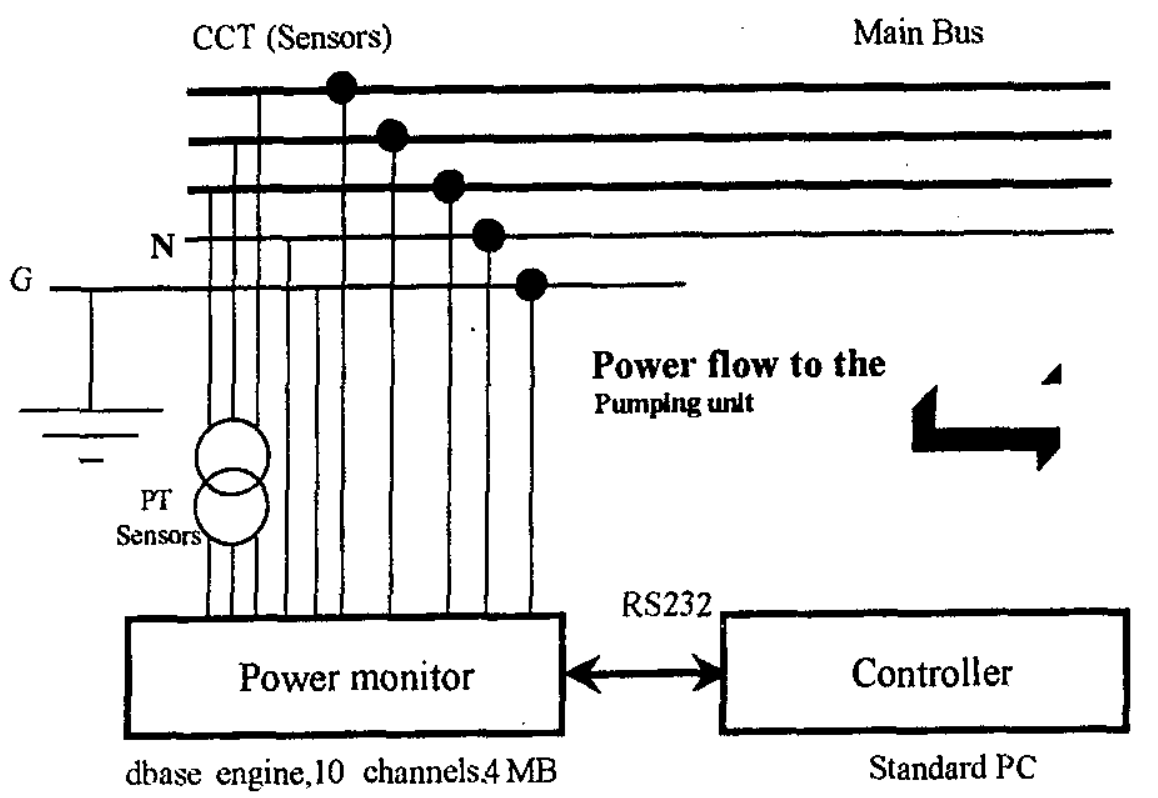

Fig. (1) diagnosis system 


\section{6- Monitoring Strategy}

The load of the pumping network stations varies according to the seasons of irrigation governed by the national scheme. Therefore, it was decided to install the monitoring system as long as possible in order to detect as much information as possible. However, long term observation confirmed that seasonal irrigation changes its pattern quarterly. Therefore, it was decided to place the monitoring system at each selected station for a continuous calendar month each quarter of the year. Over the period of measurements at each location, the monitoring was focused on:

1) Voltage variation (under voltage, transient over voltage, unbalance, and flickering).

2) Harmonic invasion and P.F conditions.

The proposed recording system permits to configure the monitor for many different sites in the same database. For each site, one can set up multiple locations where it is planned to detect the data. A location means a place represents the actual, panel or load where the monitor is physically connected. This configuration provides a proper strategy to organize information in the database and allow to group information about the related location. When connecting the on line monitor at the site, care should be exercised towards the high voltage and the necessary safety measures should be followed to avoid any personnel hazards. In Abu-Almonagga station, for instance, where the operating voltage $11 / 6 \mathrm{kV}$, all connections were carried out at the instrumentation terminals where voltage and currents are at most $110 \mathrm{~V}$ and $5 \mathrm{~A}$ respectively.

In systems using only two- current transformers, two voltage transformers, a very high balanced star resistor had to be added in order to create the star point necessary for monitoring the data. In addition a clamp on current probe was set up on the output of two current transformers to represent the image of the instantaneous current of the third line.

\section{7- Disturbances and Evaluation}

Typical disturbances have been recorded for an exploration period of 60 days: 30 days at each station over this period the sampling data were averaged at 15 minuets interval rate (sampling resolution). The monitor was set up to record all types of events in a standard tolerance graph. The following limits were used when analyzing the results (referred to the instrumentation panel)

$\begin{array}{lll}\text { Maximum phase voltage } & 127 & \text { V } \\ \text { Minimum phase voltage } & 104 & \text { V } \\ \text { Maximum neutral voltage } & 3 & \text { V } \\ \text { Maximum impulse voltage } & 500 & \text { V } \\ \text { Maximum wave-shape voltage } & 10 & \text { V } \\ \text { Max. frequency deviation } & 0.02 & \mathrm{~Hz} \\ \text { Minimum power factor } & 0.85 & \\ \text { Maximum voltage T.H.D } & 5 & \% \\ \text { Max. current T.H.D } & 20 & \% \\ \text { Maximum voltage imbalance } & 2 & \% \\ \text { Maximum current imbalance } & 5 & \%\end{array}$


Any values outside these limits are recorded in the evaluation. Values within these limits are considered to be a safe operating range.

\subsection{Voltage imbalance:}

Electrical motor drives operate satisfactory at rated load when the imbalance ratio at the rotor terminals does not exceed $1 \%$. The motor otherwise may be de-rated to $75 \%$ at $3 \%$ unbalance and $50 \%$ at $5 \%$ unbalance. Excessive voltage imbalance is an indication that one or two phases may be overloaded. A redistribution of the loads on one or more of the phases may be necessary. However, it should be understood that imbalance voltage may overheat the motor and damage electronic equipment Evaluation of the recorded results at the examined stations give the following average imbalance values shown in table (1):

Table (1) Average imbalance

\begin{tabular}{|c|c|c|}
\hline & Voltage imbalance & Current imbalance \\
\hline Station 1 & $1.503 \%$ & $2.25 \%-20.93 \%$ \\
\hline Station 2 & $0.331 \%$ & $1.43 \%-62.85 \%$ \\
\hline
\end{tabular}

It was seen that the imbalance ratio at the two stations was within the standards limits and did not cause any problems to the drive motors.

\subsection{Frequency Variation}

Any sudden variation in supply frequency will cause operating problems in induction motor driving the water pumps. Fortunately due to the large inertia of the drive system, and the strong interconnected power_network, the steady state frequency variation will not have any significant impact on the overall performance of the pumping unit. Figure (2) gives a typical record of the supply frequency at station 2. An average frequency, however, of 50.04 and $50.03 \mathrm{~Hz}$ were confirmed over the period of monitoring at station 1 and 2 respectively.

\subsection{Harmonics:}

As the stations of this pilot project are traditionally fed by normal supply source, it is expected that harmonic distortion will not present any operating problems. Table (2) gives a summary of average voltage and current distortion at station 1 and 2 . The values shown in this table are probably caused by the unpredictable events raised in the stations and recorded in the tolerance limit curve. The distortion, however, in some events has reached a value of $33.68 \%$ in phase $c$ at station 2. The values given in Table (2) are still less than the limits set up in the monitoring configuration.

Table (2) Average THD \%

\begin{tabular}{|c|c|c|c|c|}
\hline \multirow{2}{*}{} & \multicolumn{2}{|c|}{ Station 1 } & \multicolumn{2}{c|}{ Station 2 } \\
\hline & $\mathrm{V} \%$ & $\mathrm{I} \%$ & $\mathrm{~V} \%$ & $\mathrm{I} \%$ \\
\hline Phase a & 2.157 & 3.91 & 1.911 & 6.079 \\
\hline Phase b & 1.892 & 4.936 & 2.033 & 5.808 \\
\hline Phase c & 2.191 & 3.373 & 1.989 & 4.888 \\
\hline
\end{tabular}




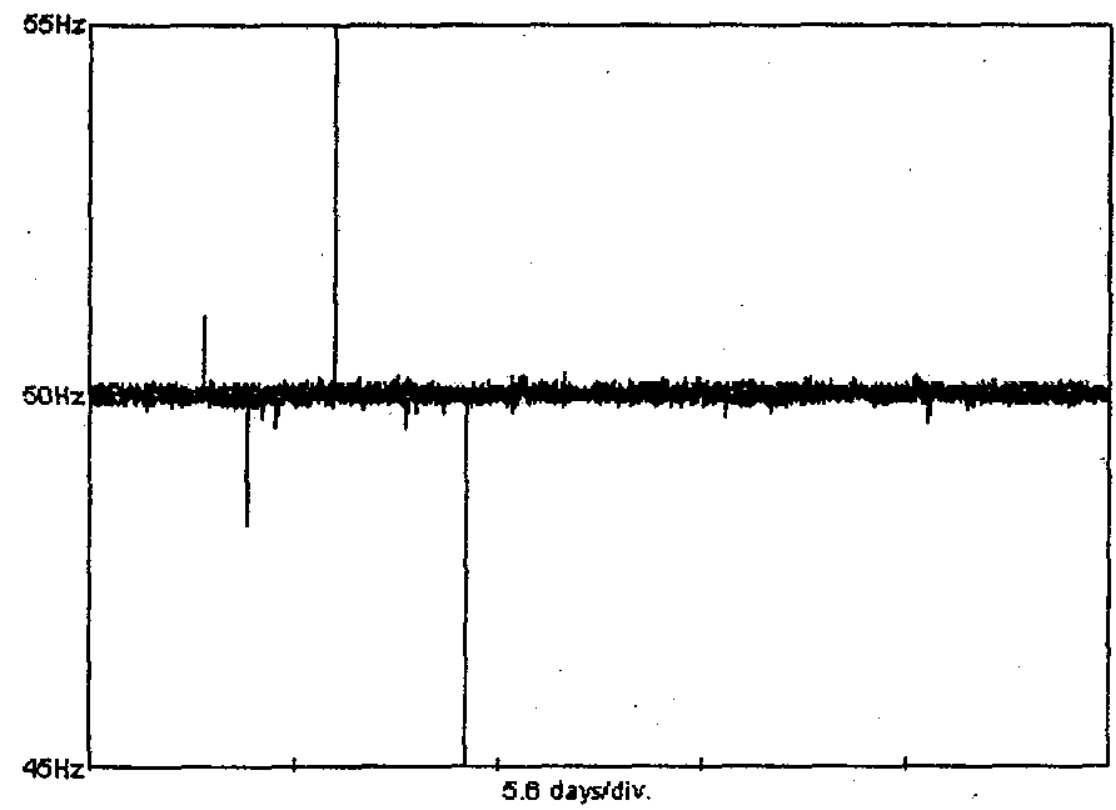

Fig. (2) Frequency variation at station 2

\subsection{Voltage Events:}

It is understood that power line disturbances are basically voltage disturbances. In addition, the duration of disturbance, not the voltage magnitude, that determines the type of disturbance. All Voltage disturbance events have recorded in a standard power tolerance envelope as shown in Fig. (3) over the period of monitoring. Each dot on this graph represents an event. The area inside the printed lines of the curve gives events that will not normally disrupt electronic equipment. The area outside the curve lines gives events, which are often associated with equipment malfunction. An equally important graph summarizes the events occurred during the same period is shown in Fig. (4). These curves are graphed by amplitude versus time of occurrence. The analysis of event graphs gives the significant concern regarding voltage variation, which is generally, the major factor affecting the performance of pumping units. This includes impulses (type I), wayeshape faults (type II), and surges/sags (type III). These events are created by changes in monitoring voltages during the experimental period of investigation. The events are generally recorded based on three different forms:

a) Transitional event: in which the $\Delta$ rms. or $\triangle$ THD is greater than the predetermined values set at the beginning of monitoring.

b) Steady state event: means the period between two transitional events during the disturbance period.

c) Impulse: high frequency surge typically caused by lightning or switching.

All events were mapped and Tables (3:5) give a summary of these recorded events at station 1 and 2 that implies the significant disturbances of the three voltage event types explained above. 


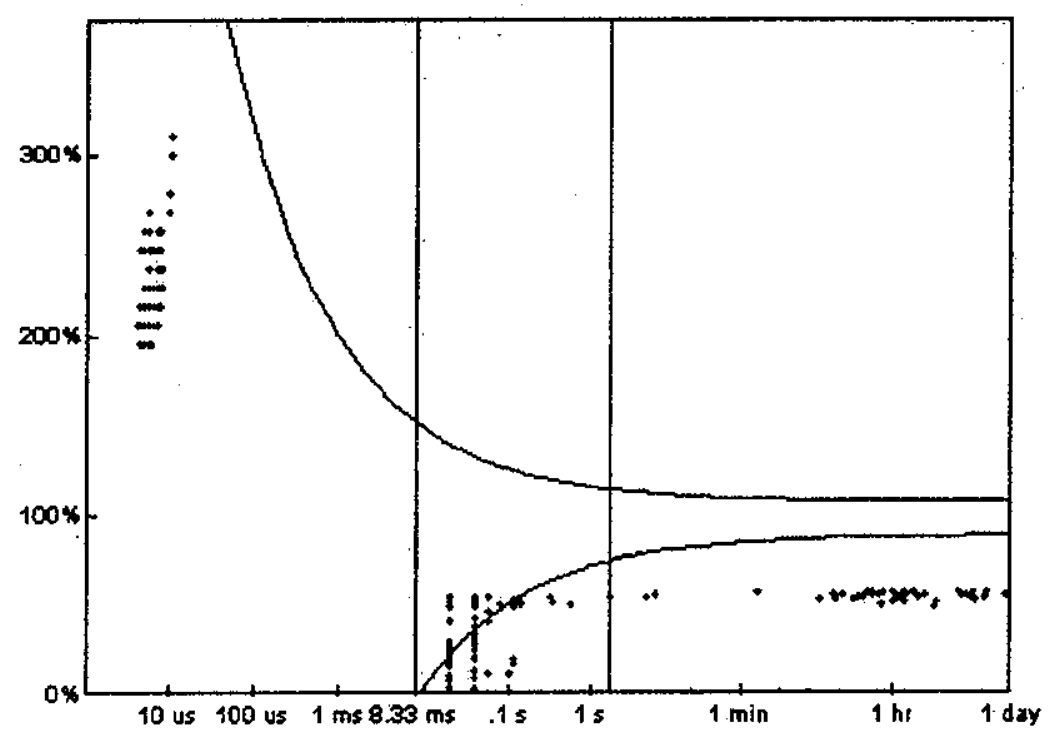

Fig. (3) envelop tolerance curve at station 2

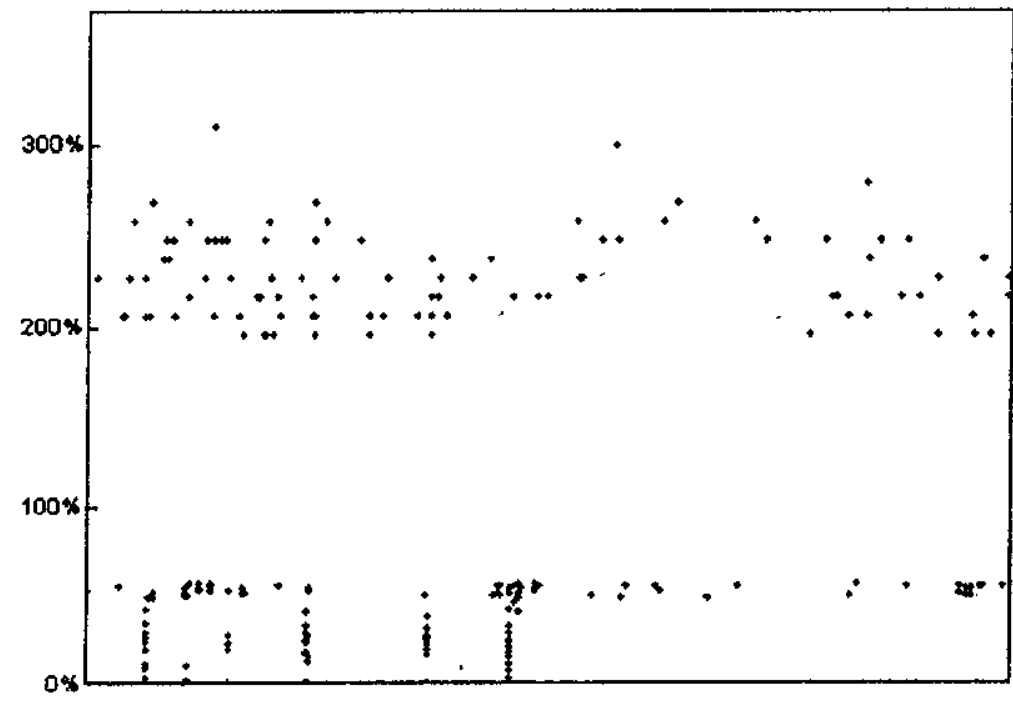

Fig. (4) Summary of events history at station 2

Table (3) Summary of recorded events

\begin{tabular}{|c|c|c|}
\hline Event & Station1 & Station2 \\
\hline Type I & 1 & 245 \\
\hline Type II & 62 & 239 \\
\hline Type III & 69 & 137 \\
\hline
\end{tabular}

Table (4) Most significant events at station 1

\begin{tabular}{|c|c|c|c|}
\hline Event & Number & Amplitude & Duration \\
\hline Type I & 52 & $80 \mathrm{kV}$ & $4.5 \mu \mathrm{sec}$ \\
\hline Type II & 860 & $5.64 \mathrm{kV}$ & $680 \mathrm{~ms}$ \\
\hline Type III & 380 & $6.838 \mathrm{kV}$ & $22.25 \mathrm{hr}$ \\
\hline
\end{tabular}


Table (5) Most significant events at station 2

\begin{tabular}{|c|c|c|c|}
\hline Event & Number & Amplitude & Duration \\
\hline Type I & 2522 & $29.2 \mathrm{kV}$ & $20 \mu \mathrm{sec}$ \\
\hline Type II & 1982 & $170.9 \mathrm{kV}$ & $140 \mathrm{~ms}$ \\
\hline Type III & 342 & $6.738 \mathrm{kV}$ & $21.79 \mathrm{hr}$ \\
\hline
\end{tabular}

\section{a) Impulse Voltage (Type I):}

Impulses are shown on the left side of the power tolerance envelope. They are known as type I. The envelope curves reported 246 impulses during the period of monitoring, at stations 1 and 2. Event 52, shown in Fig. (5) was the largest impulse at station 1 with a magnitude of $80 \mathrm{kV}$ and duration of 4.5 micro sec. In station 2, the largest event impulse was 2522 at a magnitude of $29.2 \mathrm{kV}$ and duration $20 \mathrm{p} \mathrm{sec}$. Fortunately the duration of the impulses was very small and the drive motors could ride through these disturbances. Analysis of these results realized that the main sources of these disturbances were due to lightening, switching, bad-loose connections and intermittent fault problems.

\section{b) WAVE-SHAPE FAULTS (TYPE II):}

Wave-shape faults are longer in duration than impulses and are depicted in the middle of the power tolerance envelope. The analysis showed that these waveshape disturbances were frequently associated with impulses. Monitoring results confirmed that 206 wave-shape faults occurred over the period of record at both stations. Event 342 shown in Fig. (6) is a typical wave-shape fault occurred in Station 2.

\section{c) VOLTAGE SURGES AND SAGS (TYPE III):}

In this study, surges are that rms. voltage level which goes above $+5 \%$, while sags are those voltage levels which go below $-10 \%$. The duration is generally from few a few cycles to a few seconds. A.C drive motors are generally designed for continuous operation with voltage variation of about $+10 \%$ to $10 \%$. Outside this range, the pumping unit may not perform satisfactorily. In addition. HID lighting and switchgear may be affected and raise malfunction operation due to the dip voltage faults. Surge voltage may also cause big problems in the drive motors. The insulation class should be capable to ride through this fault or a complete damage to the motor winding can occur. Monitoring records have reported 301 events for sags and surges. Event 860 shown in Fig. (7) was the most significant sag at station number 1. Analysis of these results realized that the main sources of these disturbances were due to temporary overloading or long switching in the vicinity area. Motors protection should however, be checked to ensure adequate and reliable protection against these types of faults.

\section{d) Power Factor Problem:}

Egyptian Electrical Distribution Companies have declared in January 1992 that consumers of electrical energy observed a power factor less than 0.9 lagging would be penalized considerable fine. Moreover and for incentive, the new 
regulations promised a reduced electrical tariff for consumers having their power factor ranging between 0.92 and 0.98 . For these reasons the Ministry of Water Resources and Irrigation has to check the quality of the power factor at all pumping stations and take the necessary measures for P.F correction. The records of power factor at the pilot pumping stations have showed peculiar results. This is mainly due to the continuous switching of the drive motors all over the period of operation. The definition of power factor during the transient period of starting (switching) is not well defined. That explains why the monitoring depicts these strange behaviors of P.F records shown in Fig. (8). However, the analysis of monitoring results confirmed the following total true power factor shown in table (6):

Table (6) summary of total true power factor at both stations

\begin{tabular}{|c|c|c|}
\hline & Station 1 & Station 2 \\
\hline Minimum & 0.34 & 0.287 \\
\hline Average & 0.76 & 0.84 \\
\hline Maximum & 0.838 & 0.857 \\
\hline
\end{tabular}

Station 2 has generally higher P.F because of the higher scale rating of the pumping units. Figure (9) gives the corresponding steady state phasor diagrams for station 2.

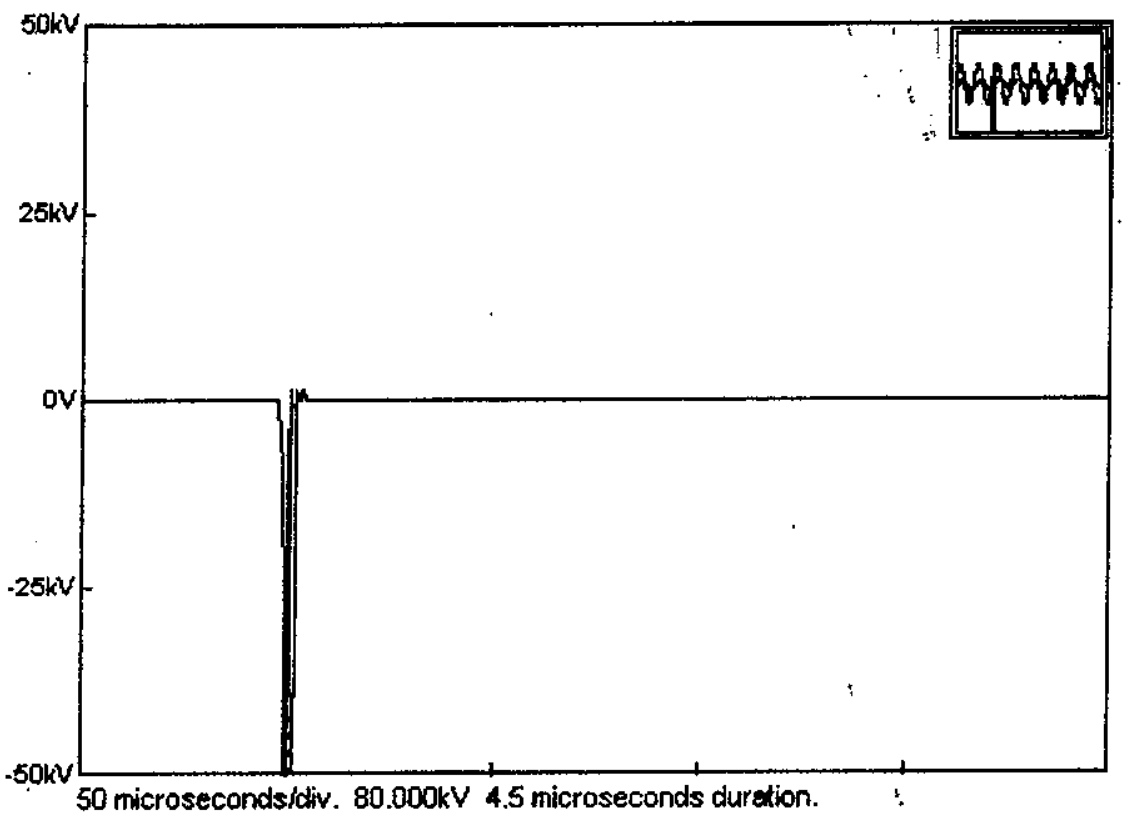

Fig. (5) Most significant event at station 1 


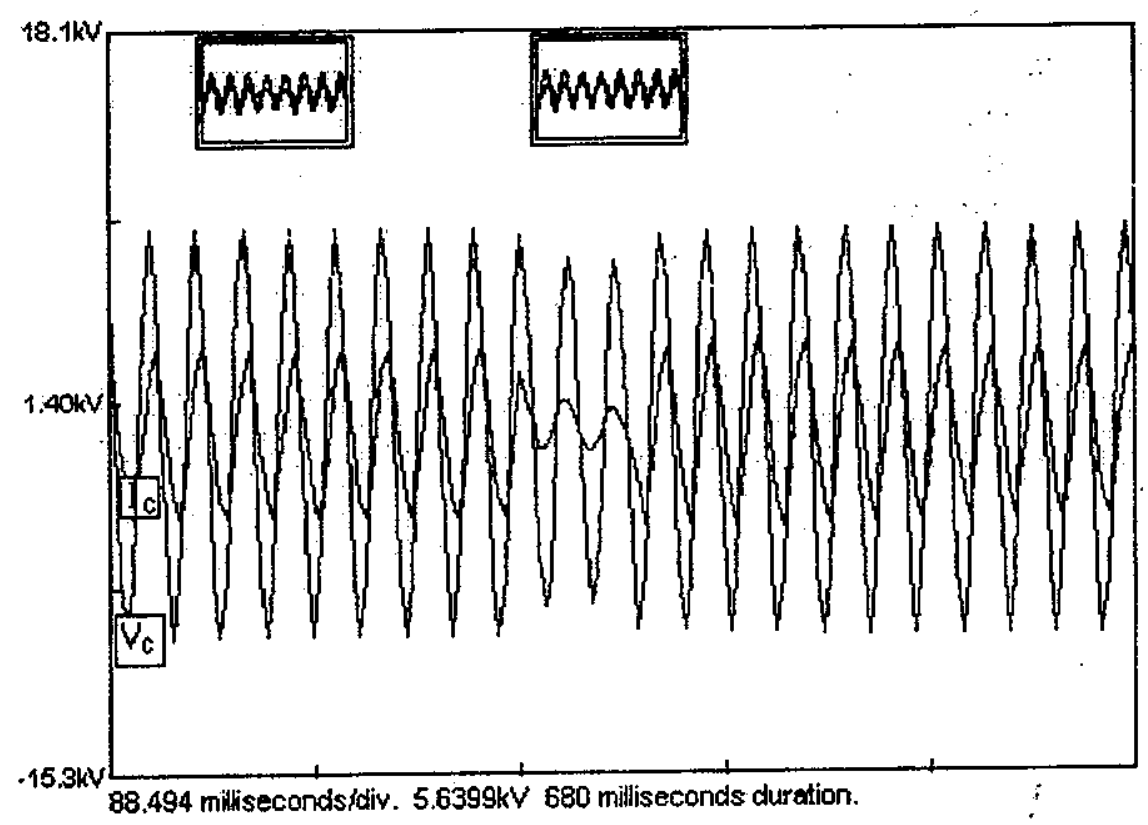

Fig. (6) Wave-shape fault at station 1

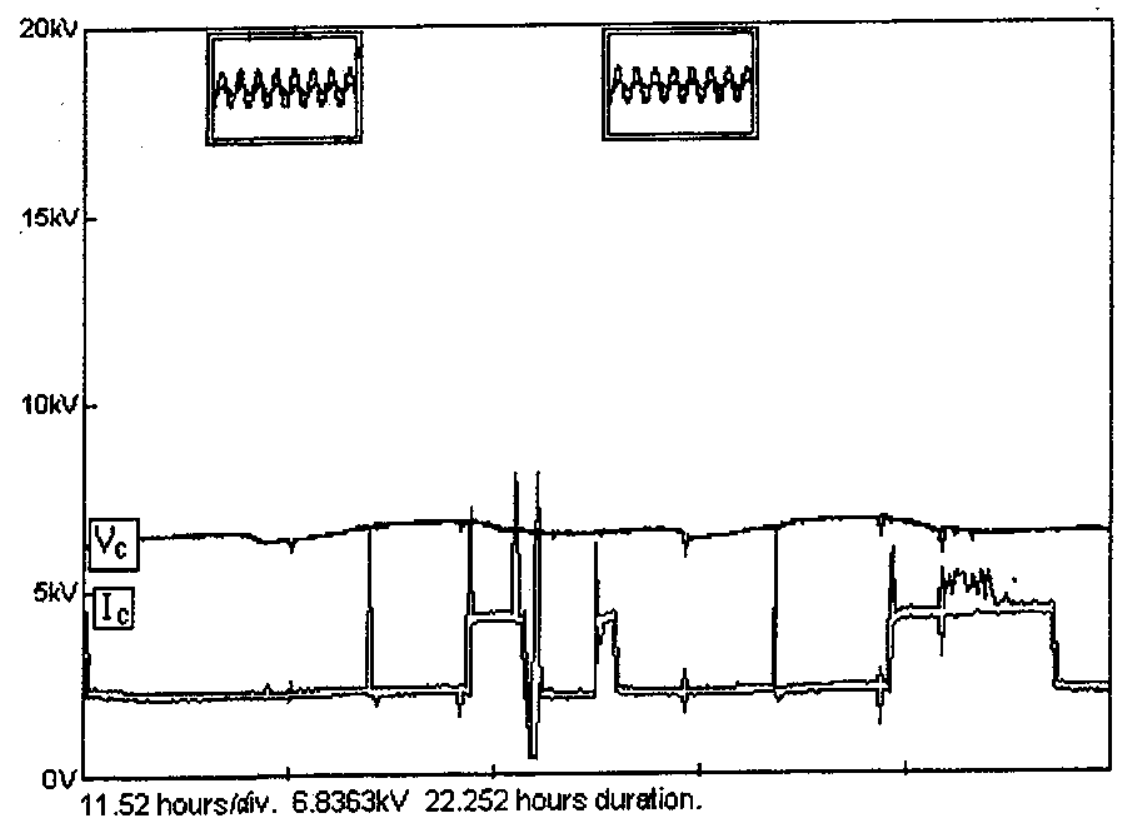

Fig. (7) Type III disturbance at station 1 


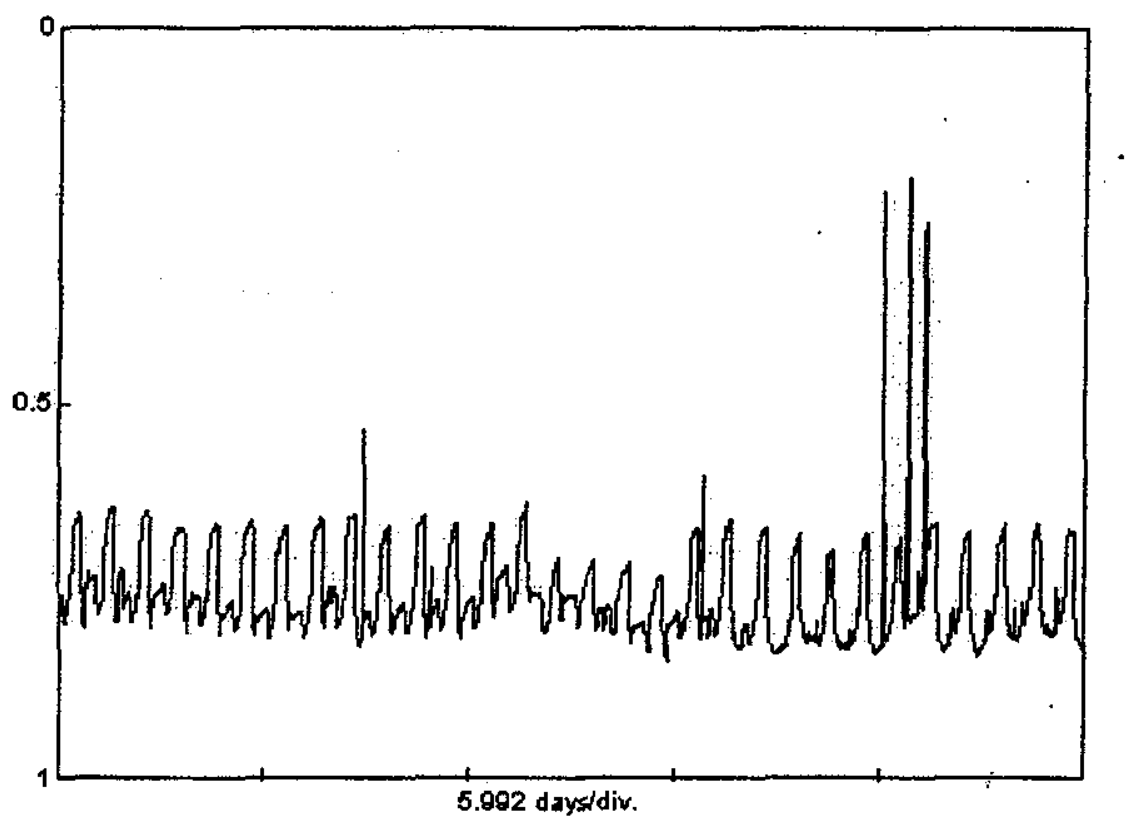

Fig. (8) Power factor variation at station 1

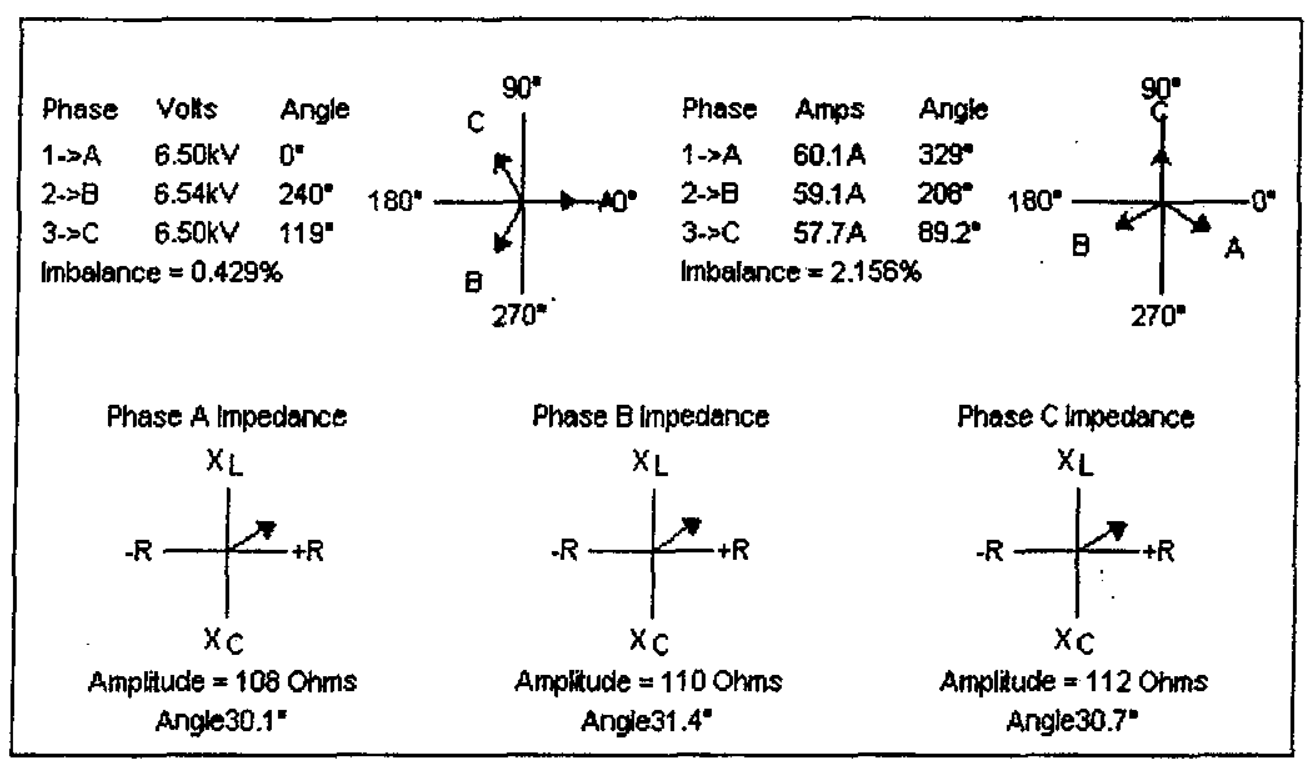

Fig. (9) Steady state phasor diagrams of station 2 


\subsection{Flickering}

Frequent starting of water pumping units is the most frequent cause of voltage fluctuation in the distribution system. Based on the duty cycle standard, the following basis is accepted at all types of pumping stations

- Infrequent starting in which interval between successive starts is more than $2 \mathrm{hr}$.

- Frequent starts in which the interval between successive starts is less than $2 \mathrm{hr}$.

Figs. (10-11) depict some typical results for the r.m.s voltage fluctuation and the percentage flickering at the pumping station 1 . The average flickering was 0.246 $\%$ with some exception event of $2.9 \%$.

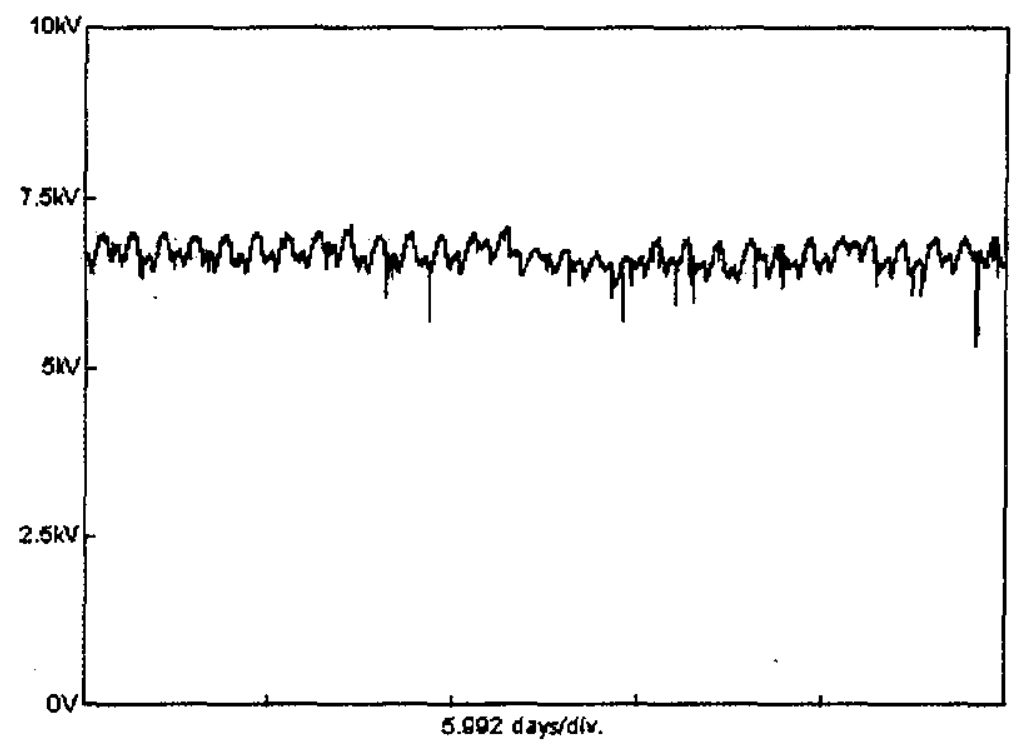

Fig. (10) Quality of r.m.s voltage at station 1

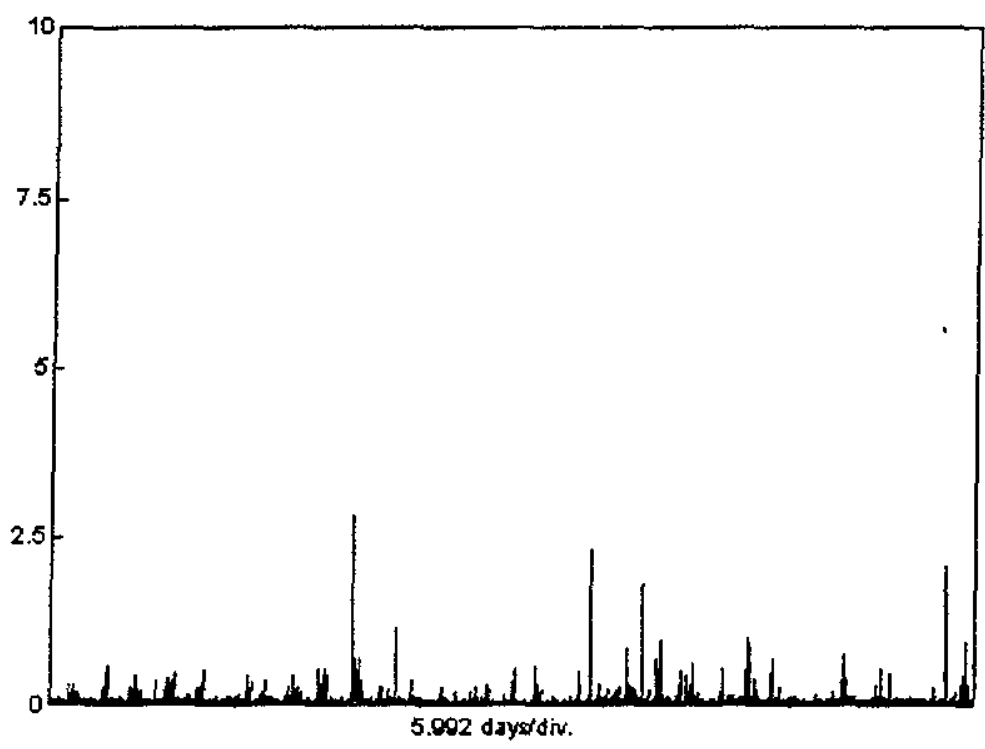

Fig. (11) Percent flickering at station 1 


\section{8- CONCLUSIONS}

Pumping stations supervised by the Ministry of Water Resources and Irrigation in Egypt seemed to operate under perfect conditions but monitoring results have proved otherwise. The investigation should be extended to clarify the picture and introduce an Integrated solution. Spikes and surges are the most inferior disturbances at the stations and surge protection should be the first priority to avoid complete loss of the drives. The results gave typical destructive impulse events of 246 . Some of which had a severe value of 7.2 p.u for a duration period of 4.5 micro-sec. Unless there are large harmonic source in the vicinity, harmonic distortions at the stations are not expected to raise any operating problems. Power factor is not easily defined at the pumping stations because of the nature of the loads and the continuous switching of the drive motors. That requires careful design for the compensating capacitor banks.

\section{9- REFERENCES}

1- Mohamed A. Helal and Radwan H. Abdel-Hamid : "Power factor report 1", Mechanical and electrical research institute of Egypt, 1997

2- Peerless pumps: "System analysis for pumping equipment selection", Document B-4003, 1997.

3- Mark McGranaghan: "Power Quality Standards", Electrotek Concepts, Inc., Internal report.

4- Christopher J. Melhorn and Mark McGranaghan: "Interpretation and Analysis of power quality measurement", Electrotek Concepts, Inc., Internal report.

5- Michael Daish: "Comprehensive Monitoring- covering all aspects", POWER QUALITY magazine, Internal report.

6- M. Negnevitsky, J. Milanovic, and M. Green: "Survey of power quality problems in Tasmania", Proceedings of the $4^{\text {th }}$ International conference on advances in power system control, Operation and Management, APSOM-97, Hong Kong, November 1997.

7- T. Gomez San Roman and J. Roman Ubeda.: "Power Quality regulation in Argentina: Flicker and Harmonics", IEEE Transaction on power delivery, Vol. 13, No. 3, July 1998

8- Ali Abur and Mladen Kezunovic.: " A simulation and testing laboratory for addressing power quality issues in power systems", IEEE Transaction on power systems, Vol. 14, No. 1, February 1999

9- D. Daniel Sabin, Thomas E. Grebe, Ashoke sundaram, and Reneaue Baird: "Preliminary results from the EPRI distribution power quality project", Electrotek Concepts, Inc., Internal report.

10- David Mueller and Jeffery Lamoree: "Detecting, Identifying, and correcting power quality problems", Electrotek Concepts, Inc., Internal report.

11-Hilger-Thomas: "power quality testing regarding to international standards", INTELEC, - International-Telecommunications-energyconference- (Proceedings). 1995, IEEE, Piscataway, NJ, USA, 95CH35824. P531-538.

12- "Motors and generators", NEMA publication MG-1, 1987.

13- "Reliable power meter", Feb., 1996 
تجليل جودة القدرة الكهريية لشبكة محطات الطلمبات بجمهورية مصر

\section{العربية}

يهدن هذا البحث بشكل رئيسى إلى مراقبة وتحليل جودة القدرة الكهربية ومدى تأثيرها علـــى

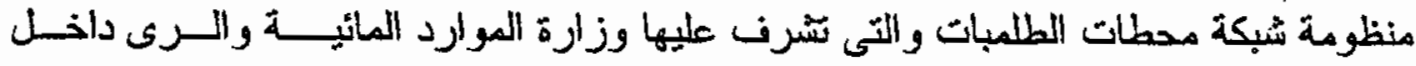
جمهورية مصر العربية.

يلخص هذا البحث إستر اتيجية مر اقبة الإضطر ابات التى تؤثر على نظام إمداد الطاقة الكهربيــة لهذه المحطات وبخاصة الإضطر ابات التى تؤثر على أداء هذه المحطات وهى:

إضظظرابات الجهد مثل إرتفاع الجهد أو إنخفاضه

التو القيات

تغيرات الجهد

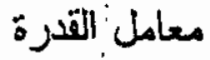

ونظر الكبر حجم واتساع شبكة محطات الطلمبات داخل جمهورية دصر العربية (اكسـثر مسـن 10. .

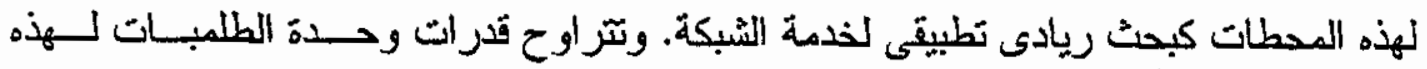

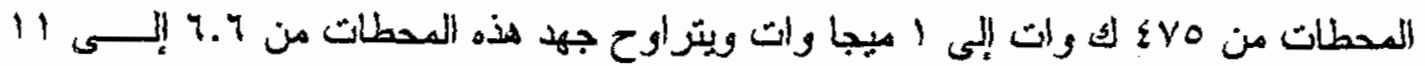

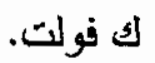

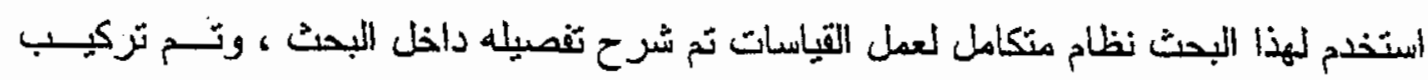

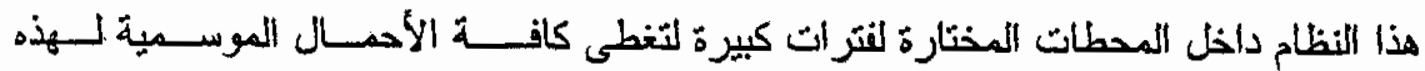

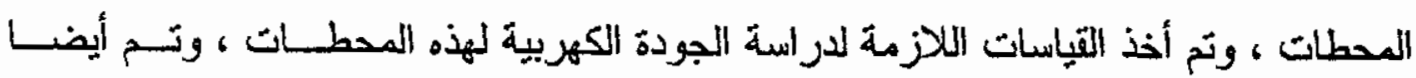

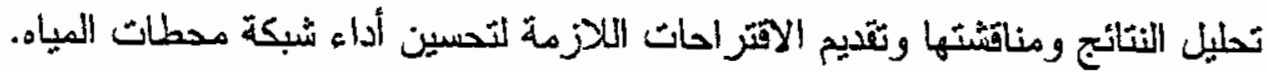

